\title{
Pemanfaatan WebGIS untuk Pemetaan Lokasi dan Kondisi Rambu Lalu Lintas Kota Banjarbaru
}

\author{
Desy Ika Puspitasari ${ }^{1}$, Al Fath Riza Kholdani ${ }^{2}$, Budi Ramadhani ${ }^{3}$, Tri Angga Tegar \\ Utama $^{4}$ \\ ${ }^{1,2,3,4}$ Program Studi Teknik Informatika, Fakultas Teknologi Informasi, Universitas Islam \\ Kalimantan MAB Banjarmasin \\ 1,2,3,4 Jl. Adhyaksa No.2 Kayu Tangi Banjarmasin. Kode Post 70123. No Telp. (0511)3304029 \\ e-mail: ${ }^{1}$ smile4desyka@gmail.com, ${ }^{2}$ kholdanialfath@gmail.com, \\ 33udiramadhani99@gmail.com, trianggategarutama@gmail.com
}

\begin{abstract}
Abstrak
Rambu lalu lintas merupakan salah satu sarana prasarana lalu lintas yang berfungsi sebagai peringatan, larangan, perintah, atau petunjuk bagi pengguna jalan. Dinas Perhubungan Kota Banjarbaru, khususnya Bidang Seksi Rekayasa dan Keselamatan Lalu Lintas memiliki wewenang dalam penyediaan dan memelihara rambu lalu lintas yang dilakukan semata-mata untuk keselamatan pengguna jalan. Kegiatan pengadaan rambu lalu lintas yang dilakukan Dinas Perhubungan Kota Banjarbaru selama ini masih mengalami kesulitan dalam merekap data baik input data rambu maupun yang diambil dari hasil survei pekerja di lapangan setiap bulannya. Pemanfaatan WebGIS diperlukan dalam menangani masalah ini, penelitian ini bertujuan memberikan informasi kondisi rambu lalu lintas dengan melakukan pemetaan titik lokasi kebutuhan beserta kondisi rambu lalu lintas guna memudahkan Dinas Perhubungan Kota Banjarbaru dalam pemeliharaan rambu lalu lintas serta menjembatani pengaduan masyarakat mengenai permintaan kebutuhan rambu. Metode system usability scale (SUS) dilakukan untuk mengetahui tingkat penerimaan user, sebanyak 14 responden dilibatkan dalam penelitian ini. Hasil penelitian menunjukkan bahwa hasil perhitungan skor SUS webGIS pemetaan lokasi dan kondisi rambu lalu lintas Kota Banjarbaru sebesar 65.6, masuk dalam kategori Marginal High dan adjective rating kategori good.
\end{abstract}

Kata kunci: lalu-lintas, pemetaan, kondisi rambu, titik lokasi, WebGIS

\begin{abstract}
Traffic signs are a means of traffic infrastructure that serves as a warning, prohibition, order, or direction for road users. The Banjarbaru City Transportation Department, specifically the Traffic Engineering and Safety Section Section has the authority to provide and maintain traffic signs that are carried out solely for the safety of road users. Traffic signs procurement activities carried out by the Banjarbaru City Transportation Department have so far been experiencing difficulties in recapitulating data both for sign input data and taken from the survey results of workers in the field every month. The use of WebGIS is needed in dealing with this problem, this study aims to provide information on the condition of traffic signs by mapping the location of the need points along with the conditions of traffic signs to facilitate the Banjarbaru City Transportation Department in maintaining traffic signs and bridging public complaints regarding demand for traffic signs. The system usability scale (SUS) method was used to determine the level of user acceptance, as many as 14 respondents were involved in this study. The results showed that the results of the calculation of the SUS webGIS score on the mapping of the location and condition of traffic signs in Banjarbaru City were 65.6, included in the Marginal High category and the adjective rating in the good category.
\end{abstract}

Keywords: traffic, mapping, signs condition, point locations, WebGIS. 


\section{Pendahuluan}

Seiring dengan kemajuan teknologi dan pembangunan di Kota Banjarbaru, maka semakin padat pula arus lalu lintas yang terjadi setiap harinya karena lalu lintas. Dinas Perhubungan merupakan salah satu instansi yang bertugas dalam menjaga dan memelihara kelancaran arus lalu lintas, dengan adanya rambu lalu lintas pada suatu jalan merupakan petunjuk bagi para pengemudi dalam berkendara. Literatur menunjukkan bahwa rambu-rambu yang tidak dirancang dan dipelihara dengan baik menghasilkan efek terhadap rambu tersebut dan pengambilan keputusan yang dilakukan saat berkendara [1].

Selama ini Dinas Perhubungan Kota Banjarbaru kesulitan dalam mengelola data rambu, baik itu lokasi kebutuhan rambu dan lokasi ketersediaan rambu beserta kondisinya. Semua data disimpan menggunakan Microsoft Word dan Microsoft Excel secara terpisah, sehingga sulit untuk melakukan rekapitulasi maupun analisis. Pada akhir tahun para pegawai Dinas Perhubungan harus merekapitulasi data kebutuhan rambu untuk diserahkan kepada pihak ketiga, sedangkan tidak adanya data ketersediaan rambu yang informatif membuat kegiatan pemeliharaan rambu menjadi tidak efektif, karena para petugas survei tidak mengetahui titiktitik rambu yang terpasang secara pasti. Bertolak dari permasalahan inilah bagaimana merancang suatu sistem yang dapat melakukan pemetaan lokasi rambu serta memantau kondisi rambu dengan memanfaatkan sistem informasi geografi yang terintegrasi dengan internet/web, untuk menunjang kegiatan serta memberi kemudahan Dinas Perhubungan dalam menganalisis data ketersediaan rambu beserta kondisinya, dan diharapkan dapat membantu memudahkan masyarakat dalam menampung informasi permintaan kebutuhan rambu serta laporan masyarakat lainnya.

Sistem Informasi Geografi (SIG) atau GIS (Geographic Information System) merupakan bentuk sistem informasi yang menyajikan informasi dalam bentuk grafis [2], dapat dimanfaatkan untuk menganalisa dan pengamatan [3], serta menampilkan data yang berhubungan dengan posisi permukaan bumi (memiliki dua bagian penting yakni informasi lokasi (spasial) dan informasi deskriptif (data non spasial/atribut)) [4]. WebGIS merupakan produk yang mengintegrasikan GIS dengan teknologi internet [5]; SIG sendiri memiliki kemampuan aplikasi terbatas pada jaringan, sedangkan webGIS memungkinkan untuk mengambil dan menganalisa data spasial [6] melalui web. WebGIS merupakan sistem lintas platform, tanpa harus peduli dengan sistem operasi apa yang digunakan oleh pengguna, pengguna dapat mengakses dan menggunakan webGIS selama memiliki akses ke internet [7]. Aplikasi web sistem informasi geografis (SIG) yang terintegrasi dengan database sistem (data non spasial) yang di unggah dirancang untuk mencapai kinerja yang lebih baik, memberikan fleksibilitas[8] dan menghasilkan aplikasi peta interaktif [9]. Rambu lalu lintas ialah bagian dari perlengkapan jalan yang memuat lambang, huruf, angka, kalimat atau perpaduannya yang memiliki fungsi sebagai peringatan, larangan, perintah atau petunjuk bagi pemakai jalan [10].

Penelitian sebelumnya yang mengangkat tema yang sama yang dilakukan oleh M. Anggris merancang aplikasi pengelolaan rambu lalu lintas menggunakan GPS, dapat dimanfaatkan untuk pemasangan dan pencarian posisi rambu [11]. Selanjutnya penelitian Ariastital \& Yokarmana yang bertujuan melakukan pemetaan sarana dan prasarana transportasi berbasis GIS di wilayah UPT Surabaya [12]. Klasifikasi rambu lalu lintas juga dilakukan oleh Campbell et al., dengan menggabungkan GIS dan Google Street View (GSV) API, untuk membantu dalam pemantauan dan pemeliharaan asset rambu lalu lintas [13]. Pendekatan yang dilakukan menunjukkan potensi menjanjikan untuk digunakan oleh otoritas pemerintah daerah.

Pada penelitian diatas membahas tentang data ketersediaan rambu atau rambu yang sudah terpasang, namun belum ada yang membahas tentang data titik kebutuhan rambu dan kondisi rambu yang telah terpasang. Tujuan penelitian ini untuk menghasilkan aplikasi berupa pemetaan lokasi dan kondisi rambu lalu lintas dengan memanfaatkan teknologi webGIS, agar menghasilkan informasi ketersediaan dan kebutuhan rambu yang efektif dan efisien. 


\section{Metode Penelitian}

Berikut adalah teknik pengumpulan data dan tahapan pengembangan perangkat lunak yang disajikan dalam bentuk Waterfall Development Model.

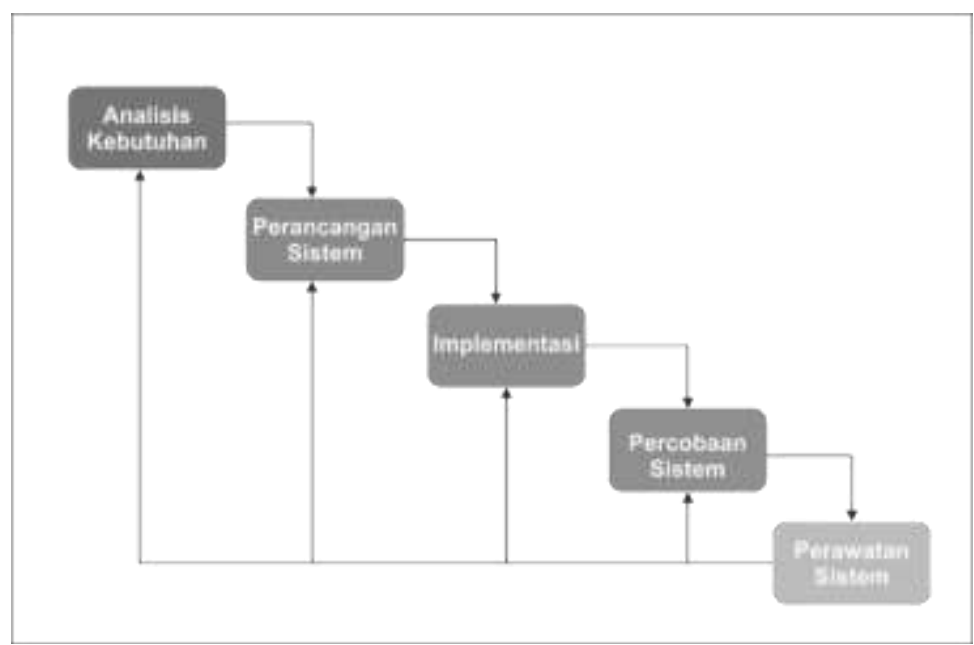

Penjelasan Gambar 1 :

Gambar 1. Waterfall Development Model

1) Analisis Kebutuhan

Menganalisis kebutuhan sistem dengan cara mengamati alur kerja yang sudah berjalan pada objek penelitian. Data yang digunakan

2) Perancangan Sistem

Merancang logika sistem yang akan dibuat, membuat rancangan basis data, serta rancangan masukan dan keluaran sistem yang dibuat. Meminta pendapat dan masukan kepada pegawai di tempat penelitian dilaksanakan.

3) Implementasi

Mulai membuat sistem, dengan mengikuti rancangan yang telah dibuat.

4) Percobaan Sistem

Mencoba sistem yang telah dibuat dengan menerapkan langsung pada kegiatan di tempat penelitian.

5) Perawatan Sistem

Melakukan perbaikan pada aplikasi apabila terjadi bug, melakukan penyesuaian ketika ada perubahan pada sistem kerja yang berjalan, dan melakukan pencadangan data.

\subsection{Desain Eksperimen}

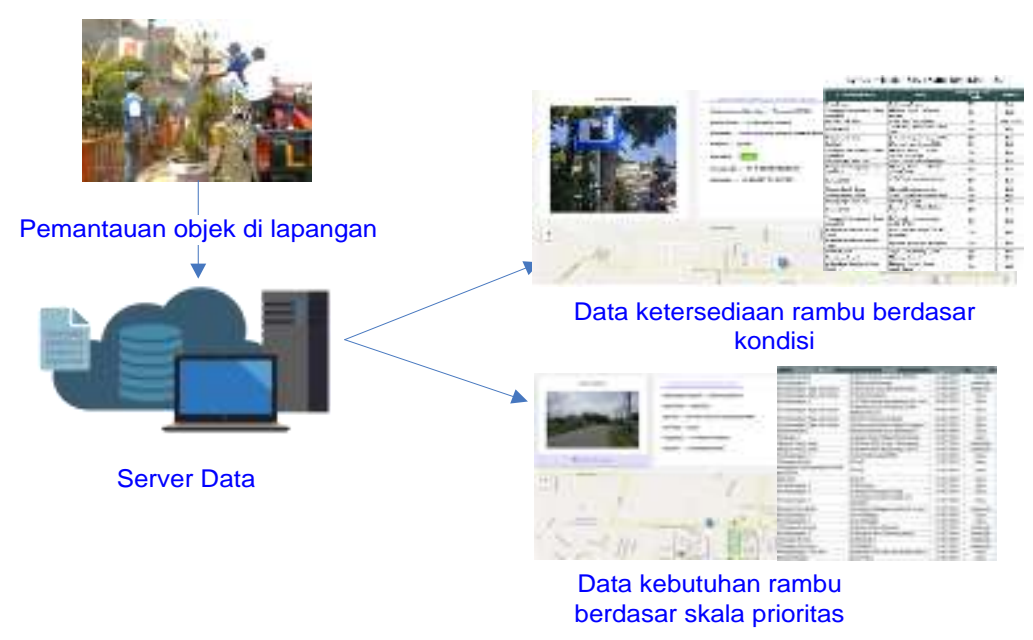

Gambar 2. Integrasi Data Survey Rambu Melalui WebGIS 
Pengumpulan data dilakukan dengan metode survey yang dilakukan untuk memperoleh data secara langsung dari sumber data lapangan dari objek yang di survey. Pada kegiatan ini banyak dilakukan pendataan baik dokumen foto rambu lalu lintas maupun kondisi objek survey. Hasil survey lapangan yang terintegrasi dengan server data mempermudah mengidentifikasi lokasi objek-objek rambu lalu lintas yang diamati. Selain itu ketersediaan rambu berdasarkan kondisi dan kebutuhan rambu berdasarkan skala prioritas dari objek yang diamati akan langsung terkumpul dan tersimpan dalam server, sehingga pengolahan database dapat dilakukan dengan cepat.

\section{Hasil dan Pembahasan}

Pada gambar 3 diagram use case ini terdapat empat pengguna yang akan terlibat namun hanya admin dan masyarakat yang akan terlibat langsung dengan aplikasi ini dimana admin mengelola data-data yang ada dan masyarakat dapat langsung menyampaikan laporan mereka jika ada permintaan mengenai lokasi yang dirasa perlu untuk dipasangi rambu lalu lintas atau sarana prasarana lalu lintas yang lain. Berdasarkan laporan masyarakat tersebut, petugas akan merespon untuk survei lapangan dan melihat kondisi lokasi.

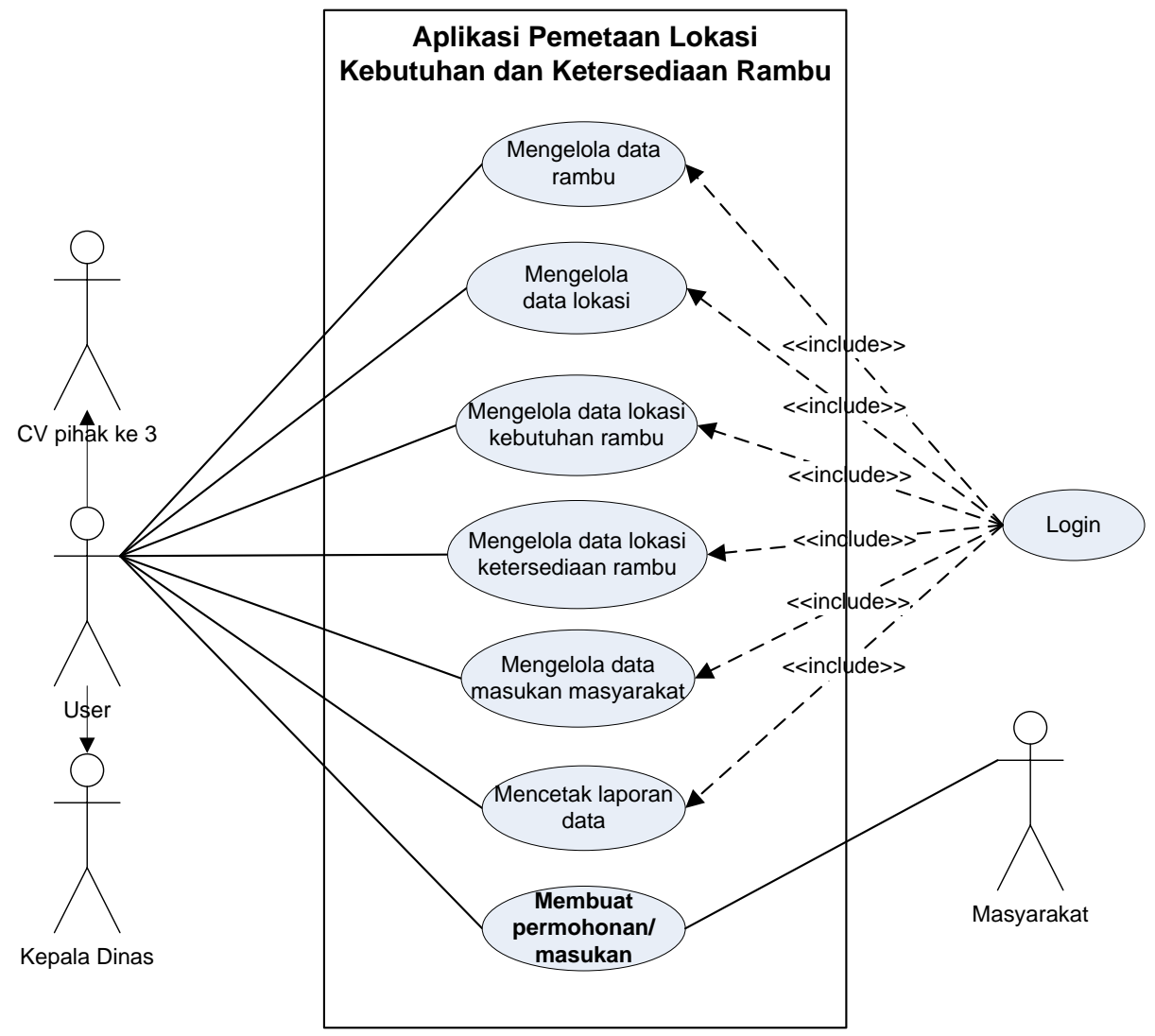

Gambar 3. Diagram Use Case

\section{Diagram Activity}

Aktivitas menambahkan data kebutuhan rambu ditunjukkan oleh gambar 3, setelah admin login dan masuk ke halaman tambah kebutuhan rambu, pastikan data rambu dan kelurahan pada data kebutuhan rambu yang akan diinput sudah ada, selanjutnya tinggal mengisi form data Kebutuhan Rambu dan menyimpan datanya.

Apabila data rambu dan kelurahan belum ada maka harus ditambahkan terlebih dahulu, agar dapat melengkapi form kebutuhan rambu, setelah data tersimpan, maka akan ditampilkan peta koordinat data lokasi kebutuhan rambu. Gambar 5 merupakan halaman untuk menginputkan data lokasi kebutuhan rambu, sedangkan gambar 6 merupakan detail lokasinya. 


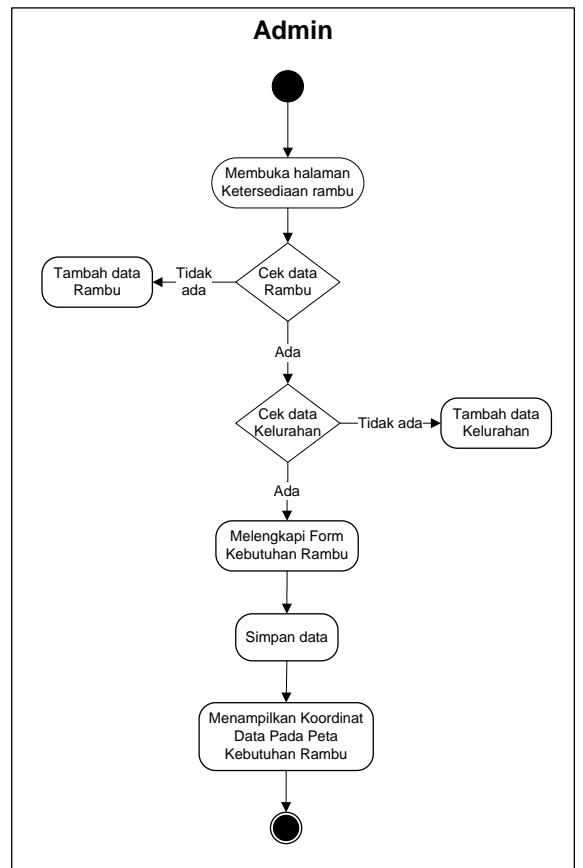

Gambar 4. Diagram activity Data Kebutuhan Rambu

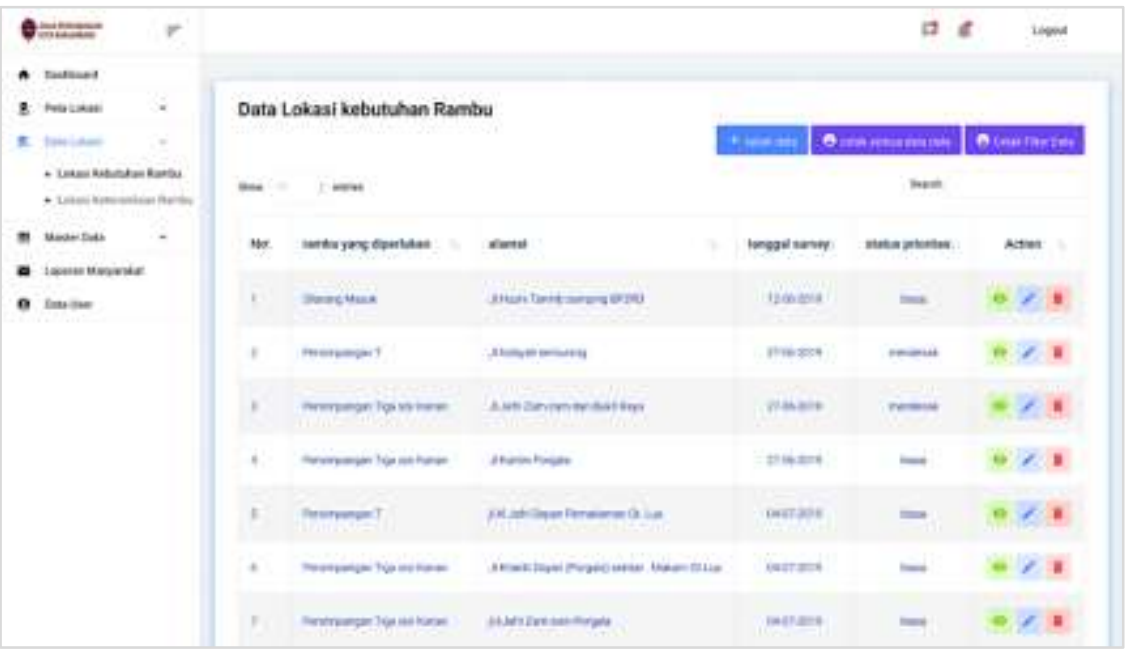

Gambar 5. Halaman Data Lokasi Kebutuhan Rambu

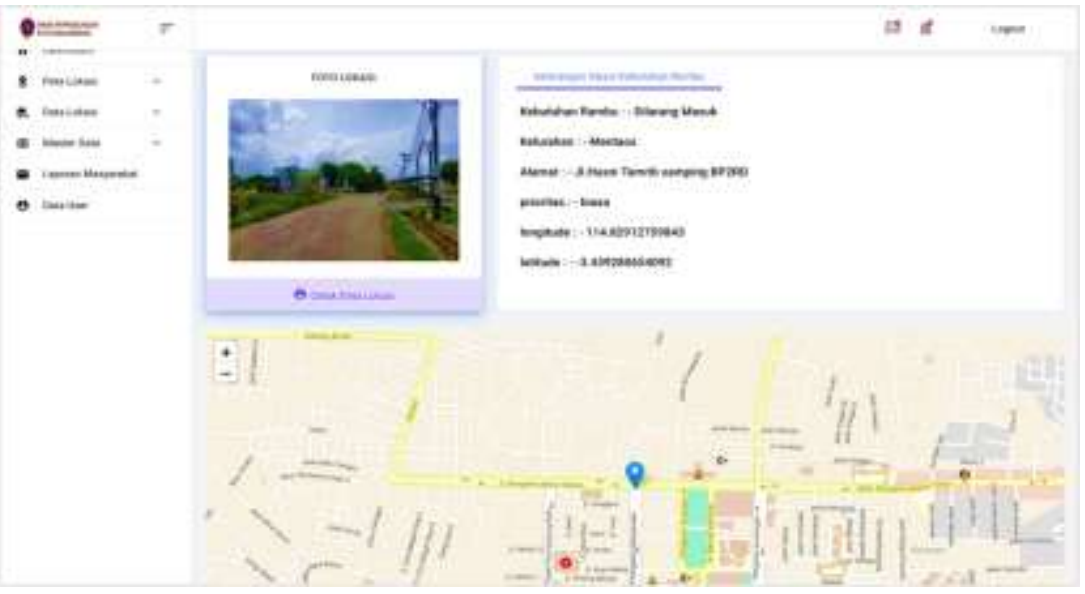

Gambar 6. Halaman Detail Lokasi Kebutuhan Rambu 
Form laporan data keseluruhan kebutuhan rambu berdasarkan skala prioritas ditunjukkan pada gambar 7, dalam sistem ini dibedakan menjadi skala mendesak dan masih baik.

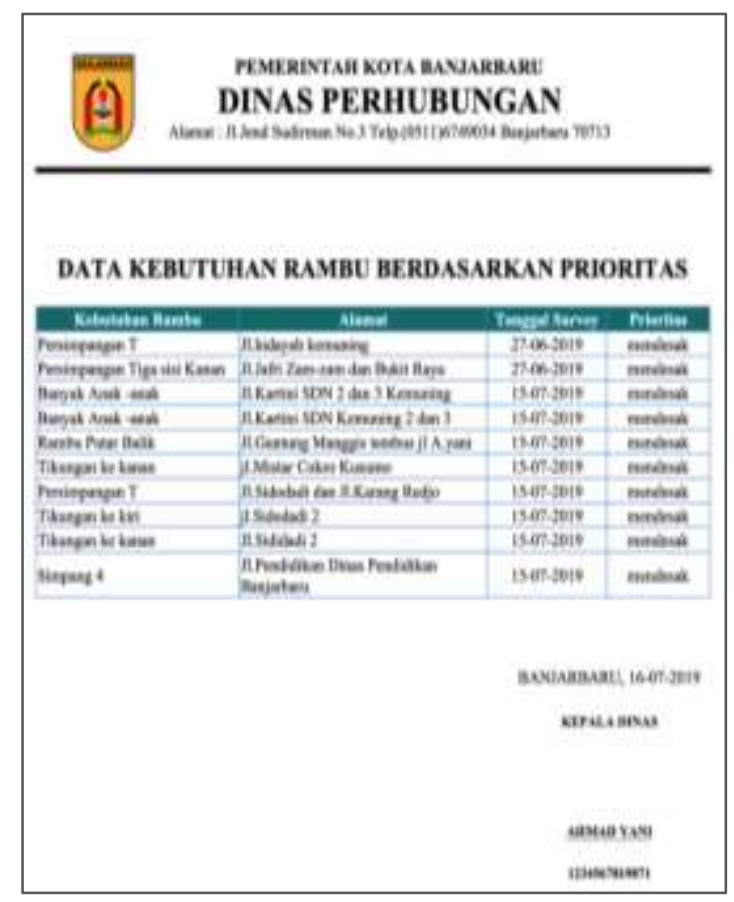

Gambar 7. Laporan Kebutuhan Rambu Berdasarkan Prioritas

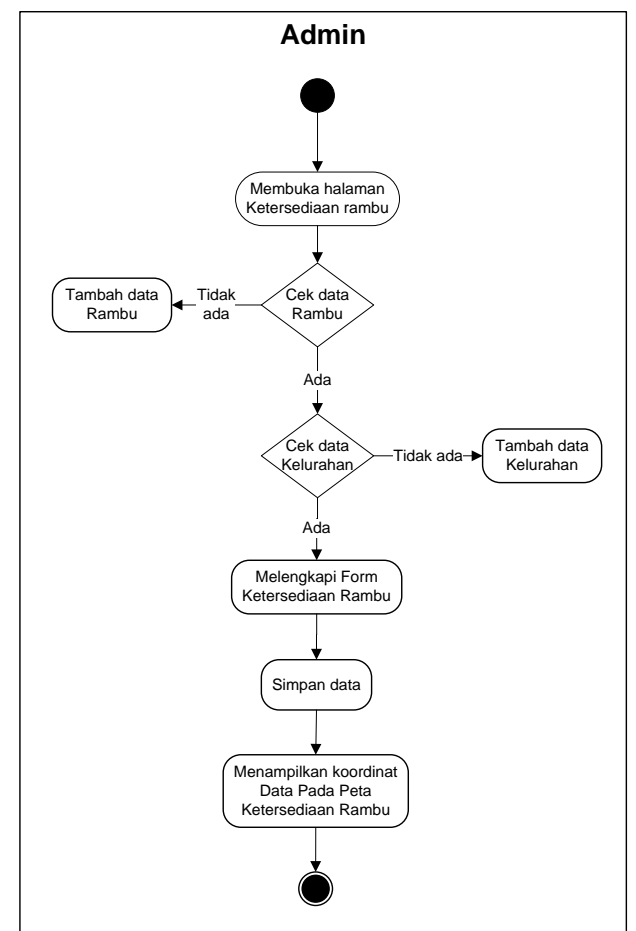

Gambar 8. Diagram Activity Data Ketersediaan Rambu

Gambar 8 merupakan aktivitas admin dalam menginput data ketersediaan rambu, apabila data rambu dan kelurahan belum ada maka harus ditambahkan dahulu, kemudian melengkapi form lokasi ketersediaan rambu pada gambar 9. Gambar 10 merupakan tampilan detail titik lokasi ketersediaan rambu. 


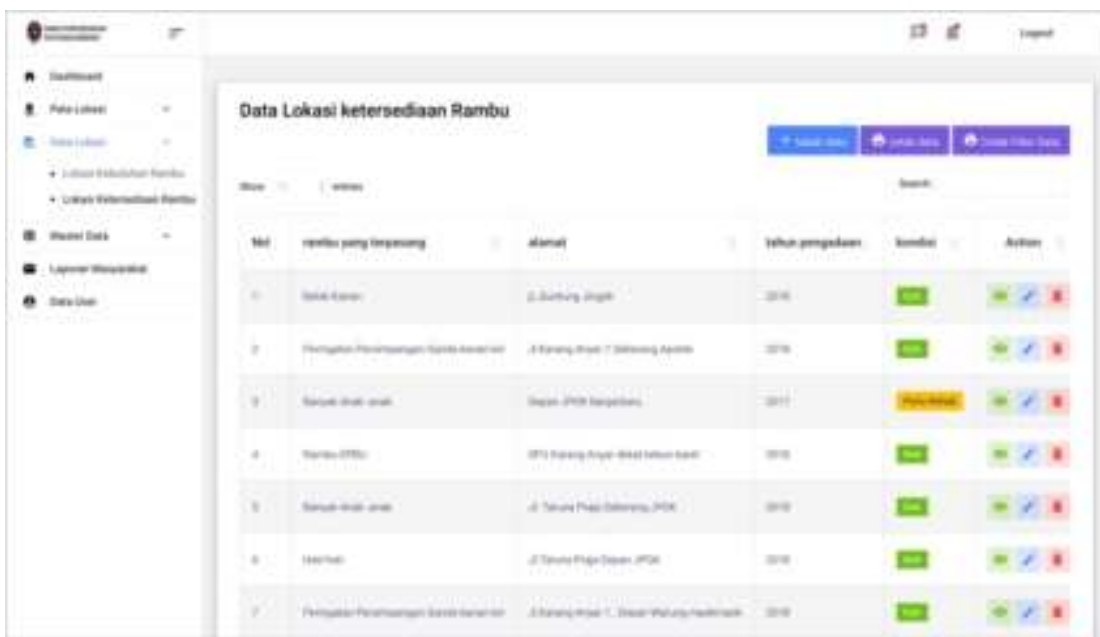

Gambar 9. Halaman Data Lokasi Ketersediaan Rambu

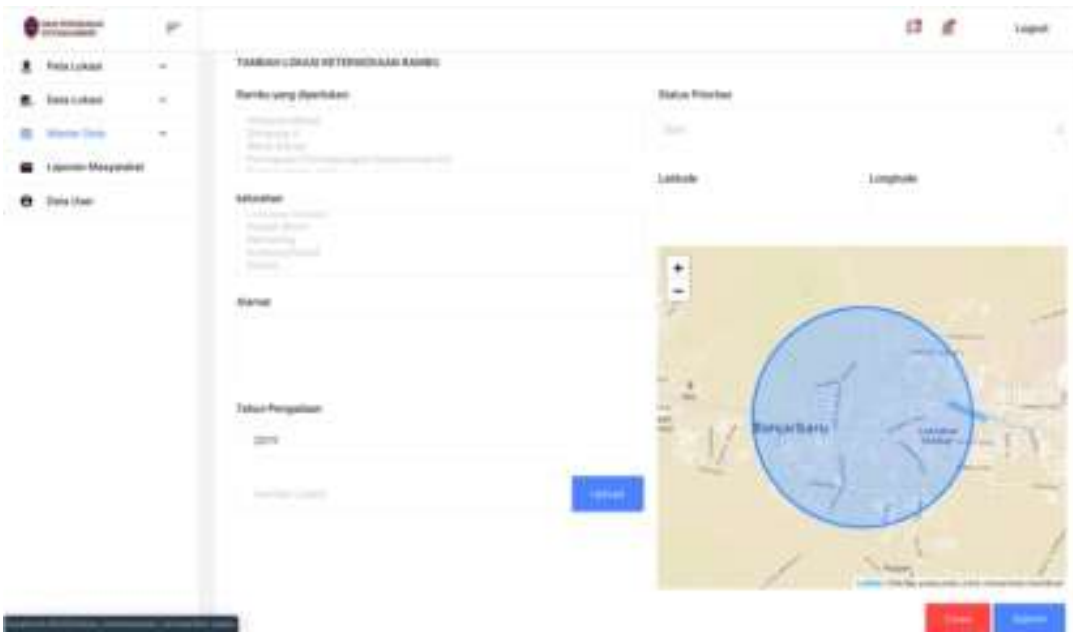

Gambar 10. Halaman Detail Titik Lokasi Ketersediaan Rambu

Gambar 11 merupakan tampilan peta seluruh titik lokasi ketersediaan rambu, yang dikategorikan dengan kondisi rambu yang masih baik, (perlu) rehab dan rusak parah. Laporan data ketersediaan rambu beserta kondisinya tersebut ditunjukkan oleh gambar 12.

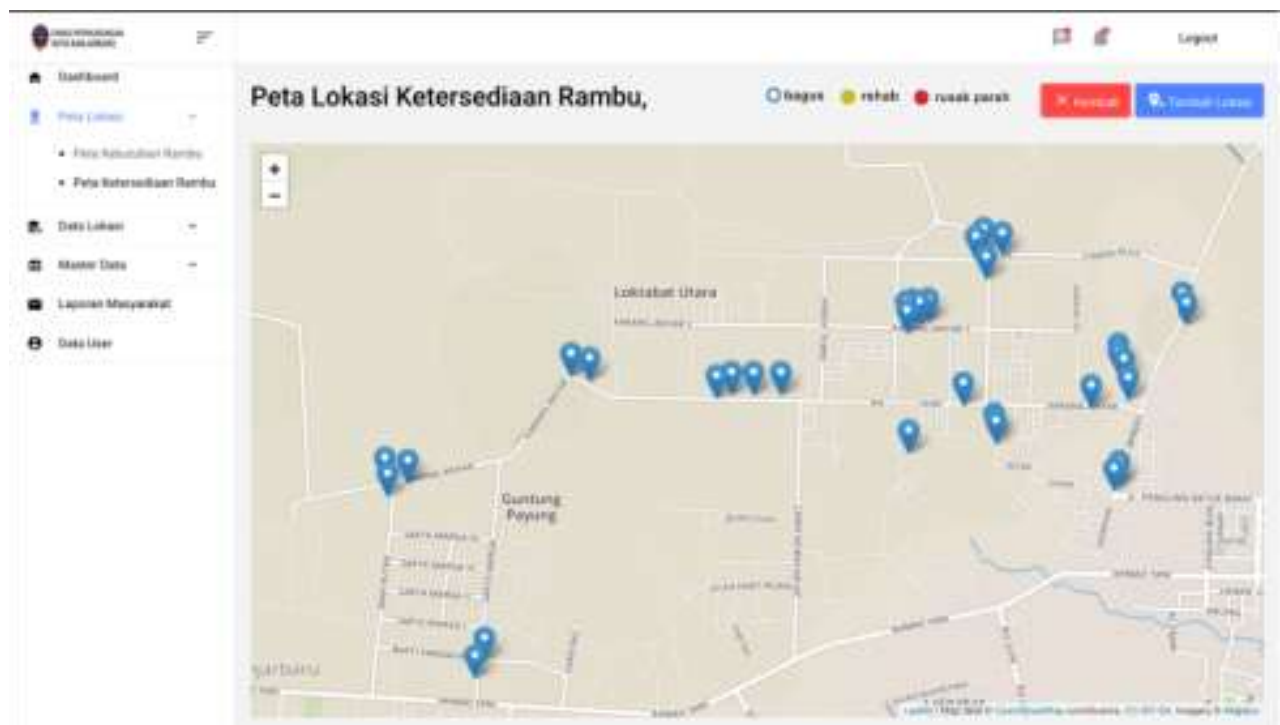

Gambar 11. Tampilan Peta Seluruh Titik Lokasi Ketersediaan Rambu 


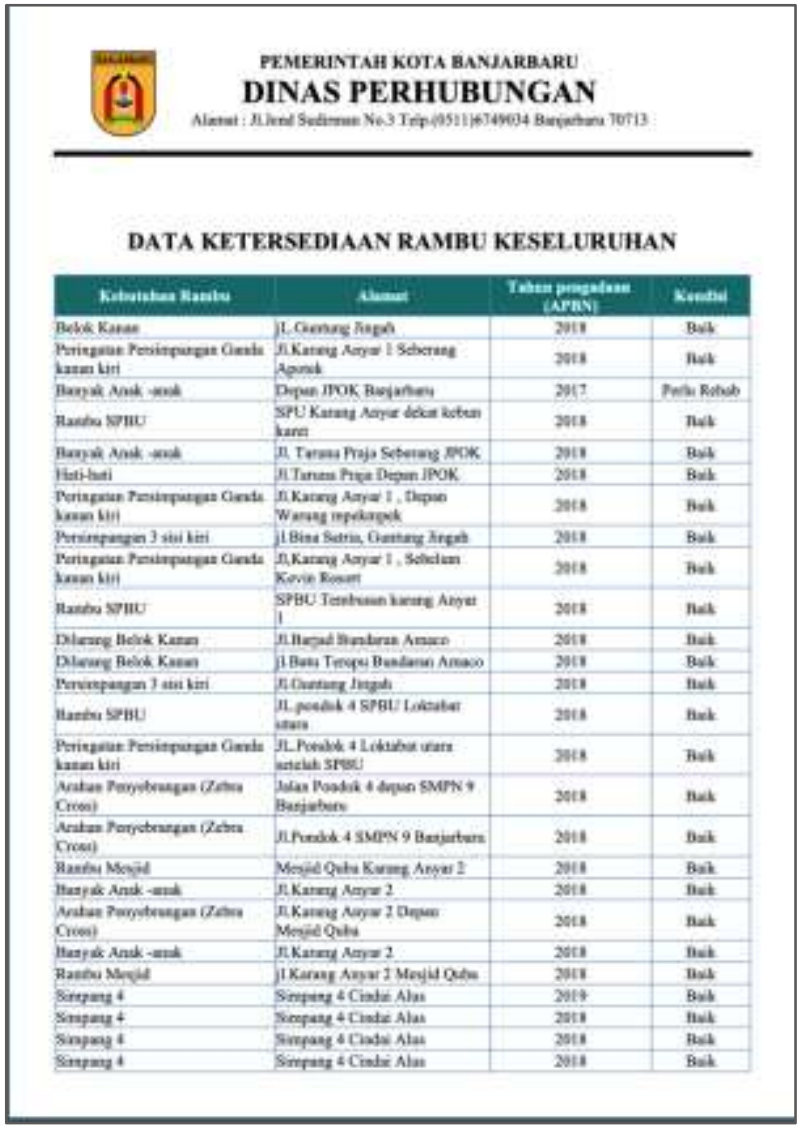

Gambar 12. Laporan Ketersediaan Rambu Berdasarkan Kondisi

Aktifitas yang diberikan kepada masyarakat pada sistem ini ialah dapat memberikan masukan apabila ada permintaan kebutuhan rambu di daerahnya, ditunjukkan pada gambar 13. Gambar 14 merupakan tampilan form untuk masukan masyarakat. Terdapat menu untuk memilih jenis rambu yang diperlukan, juga map untuk menunjukkan lokasi daerahnya.

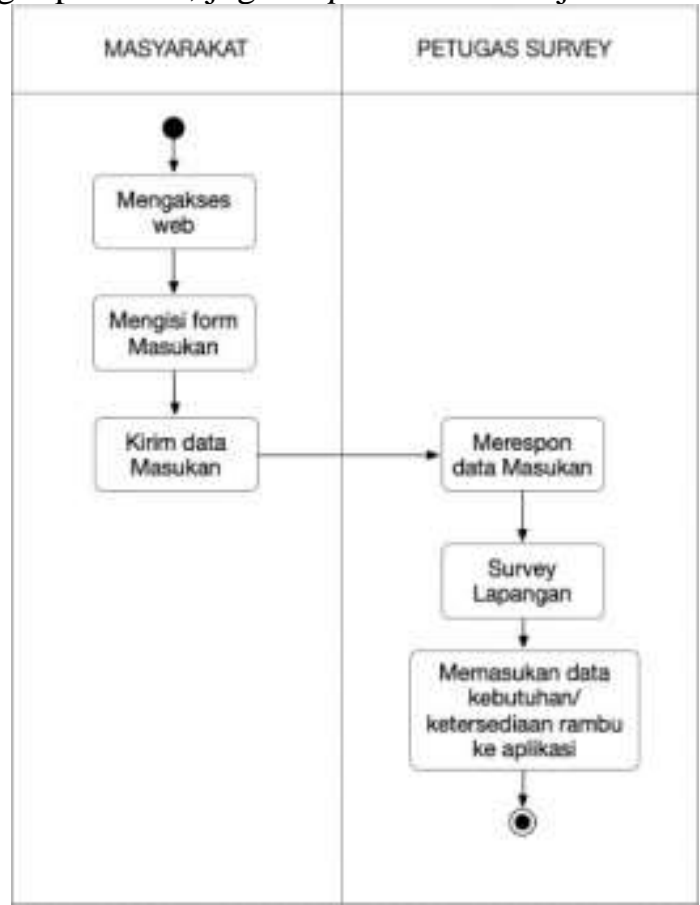

Gambar 13. Diagram Activity Proses Masukan Masyarakat 


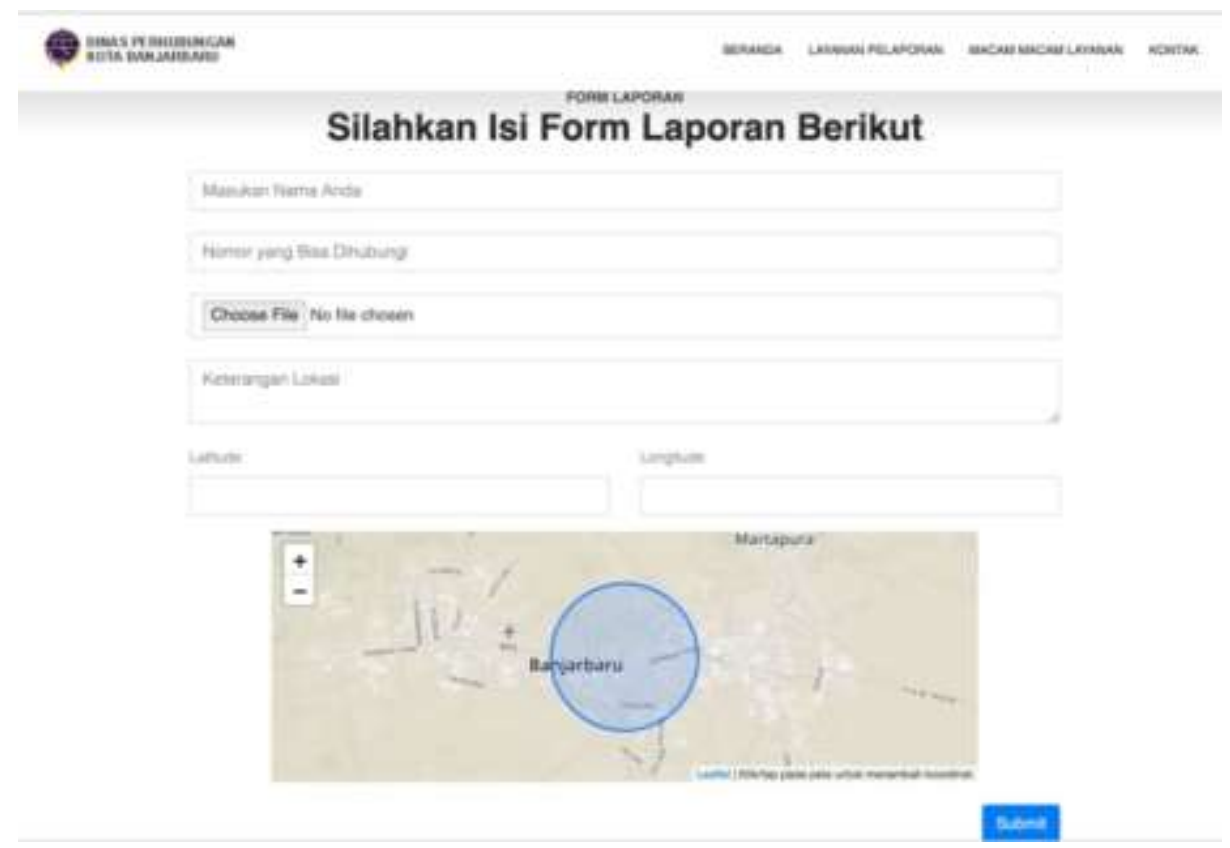

Gambar 14. Form Input Laporan Masyarakat
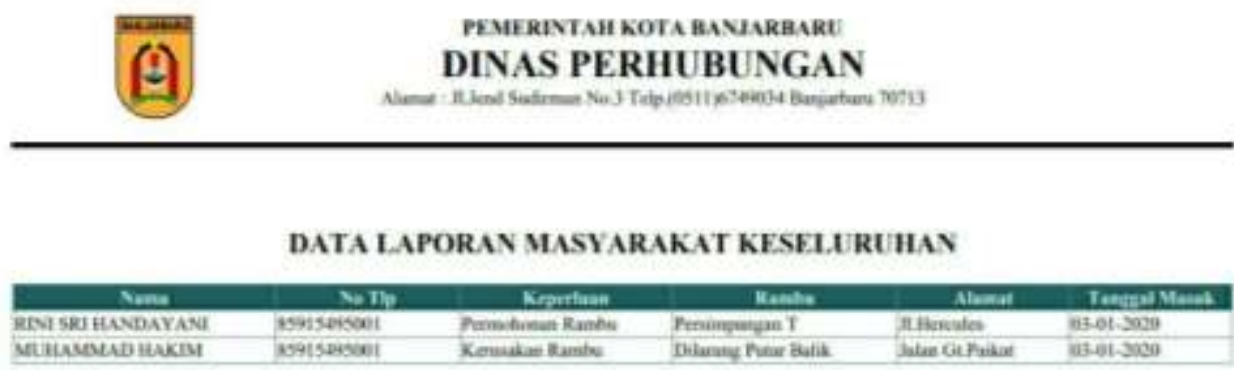

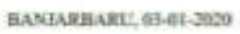

sovares

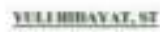

muses

Gambar 15. Form Laporan Masyarakat Keseluruhan

Laporan dari masyarakat yang ditunjukkan oleh gambar 15, terdapat menu informasi masyarakat yang melaporkan, rambu yang diperlukan, serta tanggal laporan tersebut dibuat. Berdasarkan laporan masyarakat ini, kemudian petugas mensurvey lapangan, setelah di survey dan dinyatakan layak kemudian petugas menginput data kebutuhan rambu ke dalam aplikasi sistem. Apabila rambu telah terpasang, maka akan tampil dalam form peta ketersediaan rambu.

\section{Pengujian Sistem}

Pengujian sistem yang digunakan pada penelitian ini ialah pengujian black box (black box testing), yang mengamati hasil eksekusi melalui data uji dan memeriksa fungsional dari sistem [14]. Pengujian menggunakan metode ini bertujuan agar pengguna menjalankan webGIS pemetaan lokasi ketersediaan dan kondisi rambu lalu lintas untuk menguji setiap fungsi sistem dan menilai serta memberikan status valid apabila fungsi sistem telah berjalan dengan baik. Dalam pengujian ini tidak memerlukan seorang yang ahli di bidang programming ketika 
melakukan pengujian [15]. Berikut ini merupakan tabel hasil pengujian sistem black box.

Tabel 1. Hasil Pengujian Blackbox

Pengujian $\quad$ Hasil yang diharapkan $\quad$ Hasil yang diamati

Login Admin (Username dan password jika salah)

Akan muncul pemberitahuan data user tidak cocok
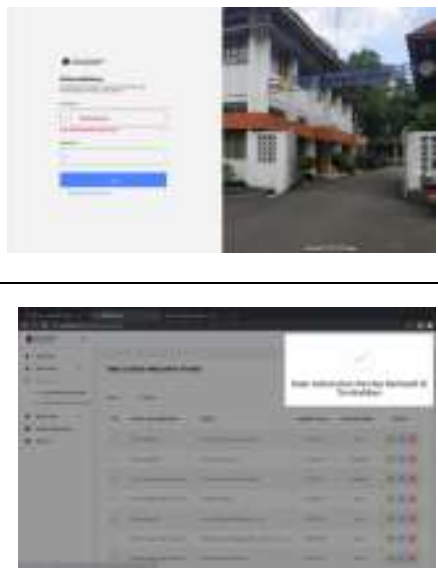

Simpan Data Kebutuhan Rambu
Berhasil menyimpan lokasi kebutuhan rambu data

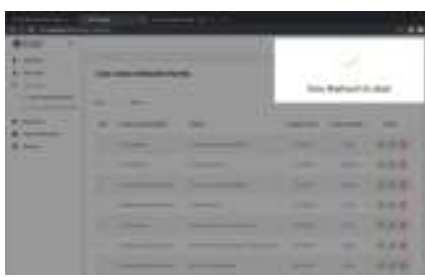

Ubah data Ketersediaan Berhasil mengubah data Rambu ketersediaan rambu

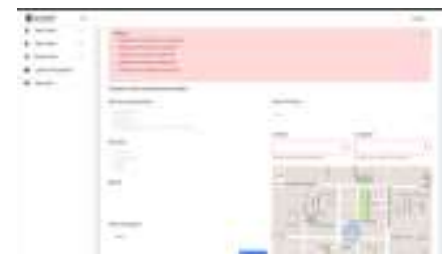

Uji Validasi kelengkapan isian

Muncul pemberitahuan error bahwa inputan harus diisi

Cetak Data

Berhasil

halaman (file menampilkan rambu

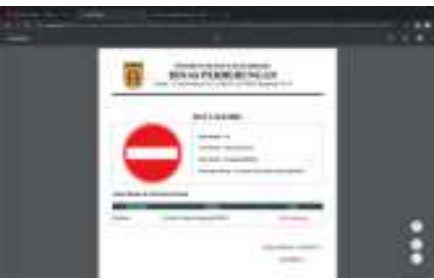

Berdasarkan pengujian sistem, dapat disimpulkan bahwa aplikasi telah memenuhi kebutuhan yang telah dijelaskan pada tabel 1 hasil pengujian black box, sebab hasil dari semua pengujian sistem pada aplikasi webGIS dihasilkan $100 \%$ valid.

\section{Pengujian Tingkat Penerimaan User (Usability)}

Pengujian tingkat penerimaan user juga diberikan pada pengguna sistem (pada kasus ini sebanyak 14 responden), berasal dari Dinas Perhubungan Kota Banjarbaru dan masyarakat umum untuk mengetahui tanggapan atau tingkat kepuasan terhadap aplikasi ini. Pengujian dilakukan dengan kuisioner, responden diminta memberikan jawaban yaitu : STS (Sangat Tidak Setuju), TS (Tidak Setuju), N (Netral), S (Setuju) dan SS (Sangat Setuju). Pengujian ini 
didasarkan pada kuisioner System Usability Scale (SUS). Berikut ini merupakan tabel pertanyaan kuisioner yang diberikan :

Tabel 2. Pertanyaan Kuisioner

\begin{tabular}{|c|c|c|c|c|c|c|}
\hline \multirow[b]{2}{*}{ NO. } & \multirow[b]{2}{*}{ PERTANYAAN } & \multicolumn{4}{|c|}{ NILAI } & \multirow[b]{2}{*}{$\begin{array}{c}\text { SS } \\
5\end{array}$} \\
\hline & & $\begin{array}{c}\text { STS } \\
1\end{array}$ & $\begin{array}{c}\text { TS } \\
2\end{array}$ & $\mathbf{N}$ & $\begin{array}{l}S \\
4\end{array}$ & \\
\hline 1 & $\begin{array}{l}\text { Apakah informasi yang disediakan oleh } \\
\text { aplikasi ini mudah dimengerti? }\end{array}$ & & & & & \\
\hline 2 & $\begin{array}{l}\text { Apakah penggunaan menu atau fitur aplikasi } \\
\text { menu mudah digunakan? }\end{array}$ & & & & & \\
\hline 3 & $\begin{array}{l}\text { Apakah dapat dengan mudah menghindari } \\
\text { kesalahan dalam menggunakan aplikasi? }\end{array}$ & & & & & \\
\hline 4 & $\begin{array}{l}\text { Apakah aplikasi ini sesuai dengan } \\
\text { kebutuhan? }\end{array}$ & & & & & \\
\hline 5 & $\begin{array}{l}\text { Secara keseluruhan apakah penggunaan } \\
\text { aplikasi ini memuaskan? }\end{array}$ & & & & & \\
\hline 6 & Apakah aplikasi bermanfaat bagi pengguna? & & & & & \\
\hline 7 & $\begin{array}{l}\text { Apakah aplikasi mempunyai kemampuan } \\
\text { dan fungsi sesuai dengan yang diharapkan? }\end{array}$ & & & & & \\
\hline 8 & Apakah aplikasi mudah dioperasikan? & & & & & \\
\hline 9 & $\begin{array}{l}\text { Apakah aplikasi ini mudah dipelajari oleh } \\
\text { orang yang baru pertama kali } \\
\text { menggunakannya? }\end{array}$ & & & & & \\
\hline 10 & $\begin{array}{l}\text { Apakah aplikasi yang dihasilkan ini akurat } \\
\text { dan dapat dipercaya? }\end{array}$ & & & & & \\
\hline
\end{tabular}

Dari hasil pengujian tingkat penerimaan user tersebut dilakukan analisa pengujian usability. Analisa tersebut ditunjukkan pada tabel berikut :

Tabel 3. Hasil Perhitungan Skor SUS

\begin{tabular}{cccccccccccc}
\hline Responden & P1 & P2 & P3 & P4 & P5 & P6 & P7 & P8 & P9 & P10 & SUS \\
\hline 1 & 5 & 5 & 5 & 4 & 4 & 5 & 5 & 5 & 5 & 4 & 47 \\
2 & 5 & 5 & 5 & 5 & 5 & 5 & 4 & 5 & 5 & 5 & 49 \\
3 & 5 & 5 & 5 & 5 & 5 & 5 & 5 & 5 & 5 & 5 & 50 \\
4 & 4 & 4 & 4 & 4 & 4 & 4 & 5 & 4 & 4 & 4 & 41 \\
5 & 5 & 5 & 5 & 5 & 5 & 5 & 5 & 5 & 5 & 5 & 50 \\
6 & 5 & 4 & 5 & 4 & 5 & 4 & 4 & 4 & 5 & 5 & 45 \\
7 & 4 & 5 & 4 & 5 & 5 & 5 & 5 & 5 & 4 & 5 & 47 \\
8 & 5 & 5 & 5 & 5 & 5 & 4 & 5 & 5 & 5 & 5 & 49 \\
9 & 5 & 5 & 5 & 5 & 5 & 5 & 5 & 5 & 5 & 5 & 50 \\
10 & 4 & 4 & 4 & 4 & 4 & 5 & 4 & 4 & 4 & 4 & 41 \\
11 & 5 & 5 & 5 & 5 & 5 & 5 & 5 & 5 & 5 & 5 & 50 \\
12 & 4 & 4 & 4 & 4 & 4 & 4 & 4 & 4 & 4 & 4 & 40 \\
13 & 5 & 5 & 5 & 5 & 5 & 5 & 5 & 5 & 5 & 5 & 50 \\
14 & 5 & 4 & 5 & 5 & 5 & 5 & 4 & 4 & 5 & 5 & 47 \\
Total Skor SUS & & & & & & & & & & $\mathbf{6 5 6}$ \\
Rata-rata Skor SUS & & & & & & & & & $\mathbf{6 5 . 6}$ \\
\hline
\end{tabular}

Tingkat penerimaan pengguna dapat ditunjukkan melalui skor SUS. Menurut A.Y. Pangestu, agar masuk dalam kategori acceptable, skor SUS harus bernilai lebih dari 70 [16]. Hasil skor tersebut disesuaikan dengan penilaian SUS seperti gambar 15 berikut. 


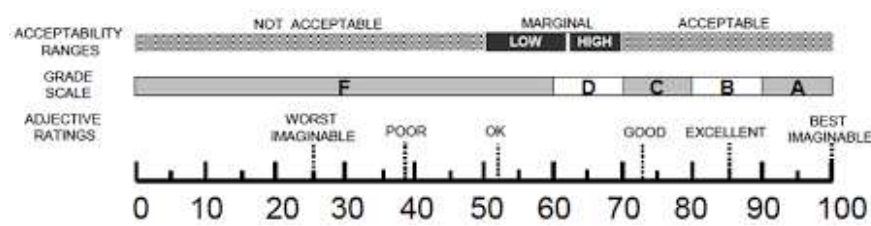

Gambar 16. Penentuan Hasil Skor SUS [16]

Tabel 3 menunjukkan hasil perhitungan skor SUS responden sebesar 656 dengan rata-rata skor SUS yaitu 65.6, masuk dalam kategori Marginal High. Skor SUS webGIS pemetaan lokasi dan kondisi rambu lalu lintas Kota Banjarbaru sebesar 65.6 masuk kategori grade scale D dan adjective rating kategori good. Namun nilai tersebut bila dibandingkan penelitian M. Anggris [11] dengan rata-rata skor SUS 79.5 dari 10 responden petugas survey dan 10 responden petugas lapangan 80.5 dengan status acceptable, maka nilai skor SUS pada penelitian ini lebih kecil.

\section{Kesimpulan}

Berdasarkan hasil dan pembahasan yang diperoleh dari perhitungan system usability scale (SUS) ditemukan dengan 14 responden, webGIS pemetaan lokasi dan kondisi rambu lalu lintas Kota Banjarbaru memiliki rata-rata skor SUS 65.6 dengan kategori marginal high yang artinya responden memiliki pandangan bahwa aplikasi webGIS sudah sesuai. Sedangkan kategori D untuk hasil grade scale dan adjective rating dengan kategori good yang artinya webGIS pemetaan lokasi dan kondisi rambu lalu lintas Kota Banjarbaru diterima dengan baik oleh responden. Hal ini salah satunya dapat disebabkan dengan jumlah dan kriteria responden. Dimana pada penelitian ini 4 responden pegawai Dinas Perhubungan dan 10 responden dari masyarakat umum yang secara umum belum menguasai penggunaan aplikasi atau latar belakang ilmu komputer. Dari hasil penelitian yang dilakukan, didapat kesimpulan terkait penggunaan metode ini dalam mengukur kualitas layanan sistem informasi, dimana kriteria responden perlu dimasukkan dalam variabel penelitian. Responden yang memiliki latar belakang ilmu komputer akan memiliki nilai kesulitan lebih kecil dibanding dengan responden tanpa latar belakang ilmu komputer, terkait pemanfaatan aplikasi dan sistem informasi.

\section{Daftar Pustaka}

[1] J. L. Vilchez, "Mental Representation of Traffic Signs and Their Classification: Warning Signs," Transp. Res. Part F Traffic Psychol. Behav. Elsevier, vol. 64, pp. 447-462, 2019, doi: 10.1016/j.trf.2019.06.004.

[2] S. M. Zulkarnain, B. Sudarsono, and A. L. Nugraha, "Pemanfaatan WebGIS Untuk Pemetaan Persebaran SPBU di Kota Semarang," J. Geod. Undip, vol. 4, pp. 19-25, 2015.

[3] S. S. Adam, M. G. Rindarjono, and P. Karyanto, "Sistem Informasi Geografi Untuk Zonasi Kerentanan Kebakaran Lahan dan Hutan Di Kecamatan Malifut, Halmahera Utara," J. Teknol. Inf. dan Ilmu Komput., vol. 6, no. 5, pp. 559-566, 2019, doi: 10.25126/jtiik.201961674.

[4] D. I. Puspitasari, Zaenuddin, and F. Yuridka, "Sistem Informasi Geografi ( SIG ) Pencarian Lokasi Tambal Ban dengan Pemanfaatan Teknologi GPS," J. ELINVO, vol. 4, no. May, pp. 30-38, 2019, doi: 10.21831/elinvo.v4i1.23146.

[5] F. Miao and Q. Yuan, "A WebGIS-Based Information System for Monitoring and Warning of Geological Disasters for Lanzhou City, China," Hindawi, vol. 2013, 2013, doi: $10.1155 / 2013 / 769270$.

[6] D. I. Puspitasari and M. Y. Kurniawan, "Location Based Services ( LBS ) for Searching Tire Repair Location in Banjarbaru City Based on Android," J. Fis. Flux, vol. Volume 1, 2019, doi: 10.20527/flux.v1i1.6150. 
[7] Z. Li, Pipeline Spatial Data Modeling and Pipeline WebGIS. Chengdu, Sichuan, China: Springer, 2020.

[8] A. Bendib, D. Hadda, and K. Mahdi, "Application of Webgis in the development of interactive interface for urban management in Batna City," J. Eng. Technol. Res., vol. 8, no. 2, pp. 13-20, 2016, doi: 10.5897/jetr2015.0579.

[9] W. Yin et al., "An Interactive Data Visualization Design Based on WebGIS," Proc. 2019 IEEE 3rd Inf. Technol. Networking, Electron. Autom. Control Conf. ITNEC 2019, no. Itnec, pp. 2462-2465, 2019, doi: 10.1109/ITNEC.2019.8729221.

[10] C. Supriatna and Sutono, "Media Sosialisasi Rambu-Rambu Lalulintas Dengan Metode Augmented Reality Berbasis Android," Media J. Inform., vol. 8, no. 1, pp. 9-17, 2016.

[11] M. F. Anggris, M. T. Ananta, and H. M. Az-zahra, "Rancang Bangun Aplikasi Augmented Reality Pengelolaan Rambu-Rambu Lalu Lintas Menggunakan Global Positioning System ( GPS ) pada Android," J. Pengemb. Teknol. Inf. dan Ilmu Komput. Univ. Brawijaya, vol. 2, no. 8, pp. 2892-2901, 2018.

[12] P. G. Ariastital and P. K. Yokarmana2, "Pemanfaatan Aplikasi Virtusee Dalam Pemetaan Prasarana Transportasi Berbasis GIS Di Wilayah UPT Surabaya," in The 2nd Conference on Innovation and Industrial Applications (CINIA 2016), 2016, no. Cinia, pp. 163-169.

[13] A. Campbell, A. Both, and Q. (Chayn) Sun, "Detecting and Mapping Traffic Signs from Google Street View Images Using Deep Learning and GIS," Comput. Environ. Urban Syst. Elsevier, vol. 77, no. May, p. 101350, 2019, doi: 10.1016/j.compenvurbsys.2019.101350.

[14] A. R. Kholdani and D. I. Puspitasari, "Sistem Informasi Manajemen Untuk Meningkatkan Daya Saing Industri Rumah Tangga," Technologia, vol. 9, no. 2, pp. 125133, 2018.

[15] Hutrianto and F. Syakti, "Sistem Informasi Geografis Penderita Malaria pada Kelurahan Cereme Taba Kota Lubuklinggau," J. Teknol. Inf. dan Komun. Digit. Zo., vol. 10, no. 2, pp. 178-188, 2019, doi: 10.31849/digitalzone.v10i2.3134.

[16] A. Y. Pangestu, R. Safe'i, A. Darmawan, and H. Kaskoyo, "Evaluasi Usability pada Web GIS Pemantauan Kesehatan Hutan Menggunakan Metode System Usability Scale (SUS)," MATRIK J. Manajemen, Tek. Inform. dan Rekayasa Komput., vol. 20, no. 1, pp. 19-26, 2020, doi: 10.30812/matrik.v20i1.709. 